\title{
Commissioning of the freight wagons with increased axle loads is a guarantee of the further development of railways of the Republic of Uzbekistan
}

\author{
Rustam Rahimov ${ }^{1 *}$, Shokhrukh Sultonov ${ }^{2}$, Otabek Nigmatov ${ }^{1}$, Meirkhan Baltaev ${ }^{1}$, Vasila \\ Ergasheva ${ }^{1}$, Liliya Filimonova ${ }^{1}$ \\ ${ }^{1}$ Tashkent State Transport University, Tashkent, Uzbekistan \\ ${ }^{2}$ Emperor Alexander I St. Petersburg State Transport University, Moscow, Russia
}

\begin{abstract}
The aim of the study is to select rational axle loads of the rolling stock and establish the conditions for their circulation on the railways of the Republic of Uzbekistan. In this work, research has been carried out to assess the indicators of the stress-strain state of rail track elements from the action of the rolling stock with various axial loads. The dynamic loads from the rolling stock wheel on the rail, tensile stresses at the edges of the rail foot, in wooden sleepers (rubber under-rail pads on reinforced concrete) under the linings, in the ballast under the sleeper, as well as stresses at the main area of the roadbed, were determined. The obtained results of studies on the determination and assessment of the loading of the elements of the permanent way and sub-grade bed under the condition of not exceeding their standard values made it possible to establish the permissible speeds of movement of freight wagons with increased axle loads of 25 and $27 \mathrm{tf}$ on the railways of the Republic of Uzbekistan, depending on the design of the track and the thickness of the ballast layer, which will increase the running and carrying capacity of the most loaded sections of the railway network, reduce operating costs, increase the volume of freight traffic by rail, which will create conditions for the further development of national rail transport in the implementation of export and transit potential.
\end{abstract}

\section{Introduction}

The possibility of introducing into operation of freight wagons with increased axle loads and arranging their circulation on the railways, depending on the structure of the permanent way, is determined by assessing the indicators of the impact of the rolling stock on the track. Various techniques have been developed to assess this impact [1-3]. However, their application is difficult due to insufficient knowledge of the quantitative assessment of the main factors affecting this interaction.

\footnotetext{
${ }^{*}$ Corresponding author: rakhimovrv@yandex.ru
} 


\section{Methods}

Currently, to determine the indicators of the impact of the rolling stock on the track on the railways of the CIS countries, including in the Republic of Uzbekistan, the "Methodology for assessing the impact of the rolling stock on the track according to the conditions of ensuring its reliability" is mainly used [4].

According to the Methodology [4] and GOST R 55050-2012 [5], the main factors influencing the loading indicators of the elements of the permanent way and the sub-grade bed include the axial load of the rolling stock; track characteristics and design: type of rail, sleepers, ballast, modulus of elasticity of the rail base, thickness of the ballast layer, the distance between the axles of sleepers and others; bogie design: mass of unsprung parts, static deflection of spring suspension, the distance between the centers of the axles of wheel pairs, wheel diameter and others; train speed.

To select rational axle loads of the rolling stock and establish the conditions for their circulation on the railways of the Republic of Uzbekistan according to the approved Methodology [4], studies have been carried out to assess the indicators of the stress-strain state of rail track elements.

Based on the analysis of the characteristics of the structures of the main, station and access roads, which are included in the balance of JSC "O'zbekiston temir yo'llari", the following track designs were selected for research [6-10]:

- rails R65 and R50 types, laid on reinforced concrete sleepers (RCS) with a profile of sleepers $1840 \mathrm{pcs} / \mathrm{km}$ on crushed stone ballast (Cs);

- R65 rails, laid on wooden sleepers of the first (I) type with a sleep pattern of 1600 and $1840 \mathrm{pcs} / \mathrm{km}$ on crushed stone ballast;

- rails R65 and R50 types, laid on wooden sleepers of the second type with a profile of sleepers 1600 and $1840 \mathrm{pcs} / \mathrm{km}$ on gravel ballast (Gr);

- R50 rails, laid on wooden sleepers of the second (II) type with a sleep pattern of 1600 and $1840 \mathrm{pcs} / \mathrm{km}$ on crushed stone ballast.

Also, the studies considered the above track designs on curved sections with a radius of $350 \mathrm{~m}$ with a sleep pattern of $2000 \mathrm{pcs} / \mathrm{km}$.

Because the share of tracks with R75 and R43 rails on the country's railways is so small (no more than $2.5 \%$ ), the design studies of tracks with these rails were not considered. Also, tracks with sand ballast were not considered since their share in the total length of tracks does not exceed $1.0 \%$ (about $70 \mathrm{~km}$ ) and are mainly available on non-public tracks, where train speeds are limited to $25-40 \mathrm{~km} / \mathrm{h}[11,12]$.

According to [13, 14], in the studies, variable values of the thickness of the ballast layer under the sleeper were taken, taking into account the ballast cushion of sand with a thickness of $20 \mathrm{~cm}$ :

- $\quad$ on crushed stone ballast: 45,50 and $55 \mathrm{~cm}$;

- $\quad$ on gravel ballast: 30,35 and $40 \mathrm{~cm}$.

The studies considered that the rolling stock is formed of freight wagons with improved indicators of dynamic impact on the track. The impact on the track of freight wagons on bogies 18-9855 with an axle load of $25 \mathrm{tf}$, wagons on bogies 18-6863 with an axle load of $27 \mathrm{tf}$ and serial freight wagons on bogies 18-100 with an axle load of 23.5 tf (table 1) was evaluated. 
Table 1. Basic technical characteristics of the wagons crew part $[15,16]$.

\begin{tabular}{|l|c|c|c|}
\hline \multicolumn{1}{|c|}{ Parameters } & \multicolumn{3}{c|}{ Bogie model } \\
\cline { 2 - 4 } & $18-100$ & $18-9855$ & $18-6863$ \\
\hline Axle loading (tf) & 23.5 & 25.0 & 27.0 \\
\hline $\begin{array}{l}\text { Weight of the unsprung parts referred to the } \\
\text { wheel (kgf) }\end{array}$ & 995 & 1035 & 1140 \\
\hline Static deflection of the spring suspension $(\mathrm{mm})$ & 48 & 51 & 70 \\
\hline $\begin{array}{l}\text { The distance between the centers of the axles of } \\
\text { the wheelsets of the vehicle bogie }(\mathrm{cm})\end{array}$ & 185 & 185 & 187 \\
\hline Wheel diameter on a rolling circle $(\mathrm{cm})$ & & 95 & \\
\hline
\end{tabular}

\section{Results and Discussion}

The dynamic load from the wheel of the rolling stock on the rail following the Methodology [4] is determined by the expression

$$
P_{\text {din }}^{\max }=P_{s t}+0.75 \cdot k_{d} \cdot\left(P_{s t}-q\right)+2.5 \cdot S
$$

where $P_{s t}$ is the static load from the wheel to the rail; $k_{d}$ is the coefficient of dynamic addition of the sprung parts; $q$ is the weight of the unsprung parts referred to the wheel; $S$ is the average deviation of the dynamic vertical load of the wheel on the rail.

The value of the coefficient of dynamic addition of the sprung parts $k_{d}$ is determined experimentally and in the absence of experimental data - by calculation. As a result of the analysis, it was stated that the experimental values of the coefficient of dynamic addition of sprung parts $k_{d}$ obtained during running dynamic tests of freight wagons on straight sections of the track, in comparison with the calculated ones according to empirical formulas on the Methodology [4, formula (5)] and according to GOST 33211-2014 [17, formula (4.12)], is less than calculated (figure $1, a, b$ ).

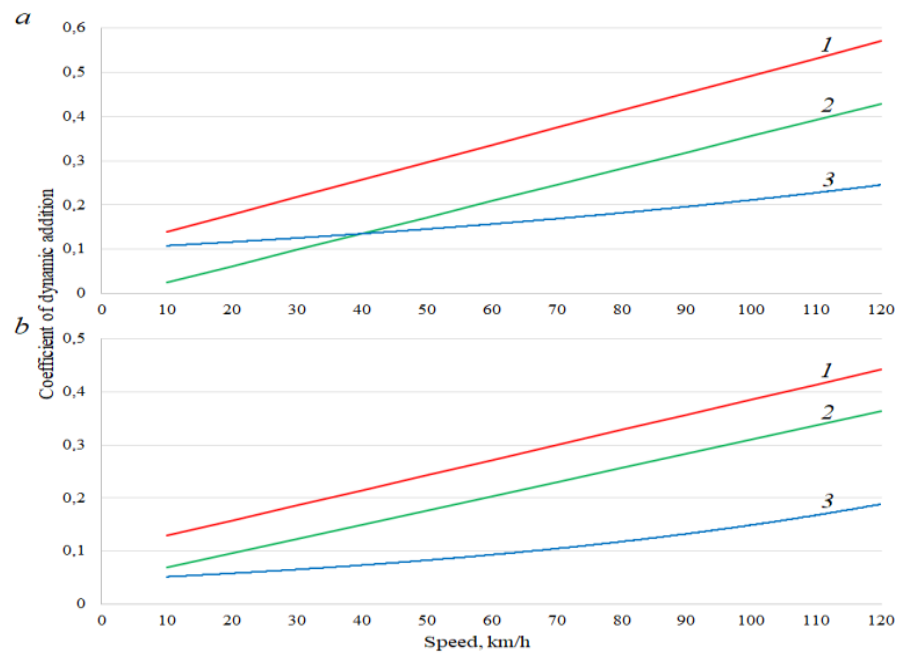

Fig.1. Dependence of the coefficient of dynamic addition of sprung parts of a freight wagon with an axle load of $25 \mathrm{tf}(a)$ and $27 \mathrm{tf}(b)$ on the speed of rolling stock: 1 is calculation according to the Methodology [4]; 2 is calculation according to GOST 332112014 [17]; 3 is experiment. 
Dependences obtained by expression (1) and experimental values of dynamic loads on a typical track structure (with R65 rails laid on reinforced concrete sleepers with a sleep pattern in straight track sections $1840 \mathrm{pcs} / \mathrm{km}$ on crushed stone ballast) on the speed of rolling stock on straight sections are shown in figure 2.

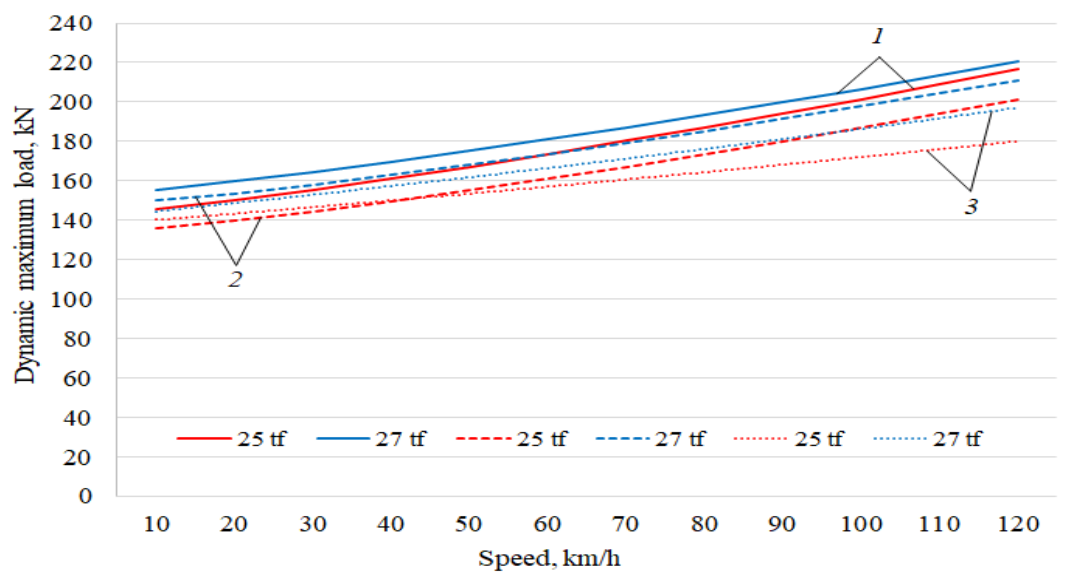

Fig. 2. Dependence of the dynamic maximum loads on the speed of the rolling stock with axial loads of 25 and $27 \mathrm{tf:} 1$ is according to the calculated values $k_{d}$ according to the Methodology [4]; 2 is according to the calculated values $k_{d}$ according to GOST 332112014 [17]; 3 are experimental values

According to the research results, it was found out that the experimental values of the dynamic maximum loads from the wheels on the rails are less than the calculated ones. Therefore, in the future, the load indicators of the track elements were calculated with the loads obtained by the calculation formula, according to the Methodology [4], which will ensure the safety margin of the track elements.

As an assessment criteria for the force impact of the rolling stock on the track in accordance with the Methodology [4] and GOST R 55050-2012 [5], the indicators given in table 2 were taken.

Table 2. Evaluation criteria for track strength

\begin{tabular}{|c|c|c|}
\hline Criteria & $\begin{array}{c}\text { Unit of } \\
\text { measurement }\end{array}$ & $\begin{array}{c}\text { According to } \\
\text { GOST R 55050-2012 [5] }\end{array}$ \\
\hline $\begin{array}{l}{\left[\sigma_{\mathrm{k}}\right]-\text { allowable tensile stresses in the edges of the }} \\
\text { rail foot }\end{array}$ & \multirow{4}{*}{$\mathrm{MPa}$} & 240 \\
\hline $\begin{array}{l}{\left[\sigma_{\text {sl }}\right]-\text { permissible collapse stresses in wooden }} \\
\text { sleepers (pads on reinforced concrete) under pads }\end{array}$ & & 2.2 \\
\hline $\begin{array}{l}{\left[\sigma_{\mathrm{b}}\right]-\text { allowable compressive stress in the ballast }} \\
\text { under the sleeper }\end{array}$ & & $\begin{array}{l}0.5 / 03 *(* \text { for track with } \\
\text { gravel ballast })\end{array}$ \\
\hline $\begin{array}{l}{\left[\sigma_{\mathrm{h}}\right] \text { - allowable compressive stresses on the main }} \\
\text { site of the subgrade }\end{array}$ & & 0.08 \\
\hline
\end{tabular}

The assessment of the impact of freight wagons with increased axle loads on the track was made by comparing the data obtained from the results of stress calculations with their permissible values according to GOST R 55050-2012 [5], as well as with those obtained during operation on the railway network of freight wagons on bogies of traditional design (models 18-100) with an axle load of $23.5 \mathrm{tf}$. 
Tensile stresses in the edges of the rail foot are considered to be the determining parameter of the rail strength, which, following the Methodology [4], are calculated by the formula:

$$
\sigma_{k}=f \cdot \sigma_{0}
$$

Here $f$ is the coefficient of transition from axial stresses in the rail foot to edge stresses; $\sigma_{0}$ is maximum stresses in the rail foot from its bending under the action of the moment $M$, which are determined by the expression,

$$
\sigma_{0}=\frac{M}{W}=\frac{P_{d i n}^{\max }+\sum \mu_{i} P_{a v}}{4 k W}
$$

where $W$ is the moment of resistance to bending of the rail to the axis passing in the plane of its foot; $k$ is coefficient taking into account the relative stiffness of the rail base and the rail; $\mu_{i}$ is ordinates of the line of influence of bending moments of the rail in the sections of the railway track; $P_{a v}$ is the average value of the vertical force from the wheel to the rail.

The calculation results obtained by formula (2) are shown in figure 3 . It can be seen that the highest values of edge stresses in the rail foot in all considered track structures, except for R50(6)2000(II)Cs and R50(6)2000(II)Gr, do not exceed the established permissible values of $240 \mathrm{MPa}$ according to GOST R 55050-2012 [5] when operating freight wagons with an axle load of up to $27 \mathrm{tf}$ at a speed of $90 \mathrm{~km} / \mathrm{h}$, which meets the requirements of the Rules for the technical operation of railways of the Republic of Uzbekistan (RTO) [12]. On tracks with type II wooden sleepers R50(6)2000(II)Cs and R50(6)2000(II)Gr for not exceeding the established allowable values of $240 \mathrm{MPa}$ following GOST R 55050-2012 (figure 3) when operating freight wagons with the axle with a load of $27 \mathrm{tf}$, it is necessary to limit the speed to $80 \mathrm{~km} / \mathrm{h}$.
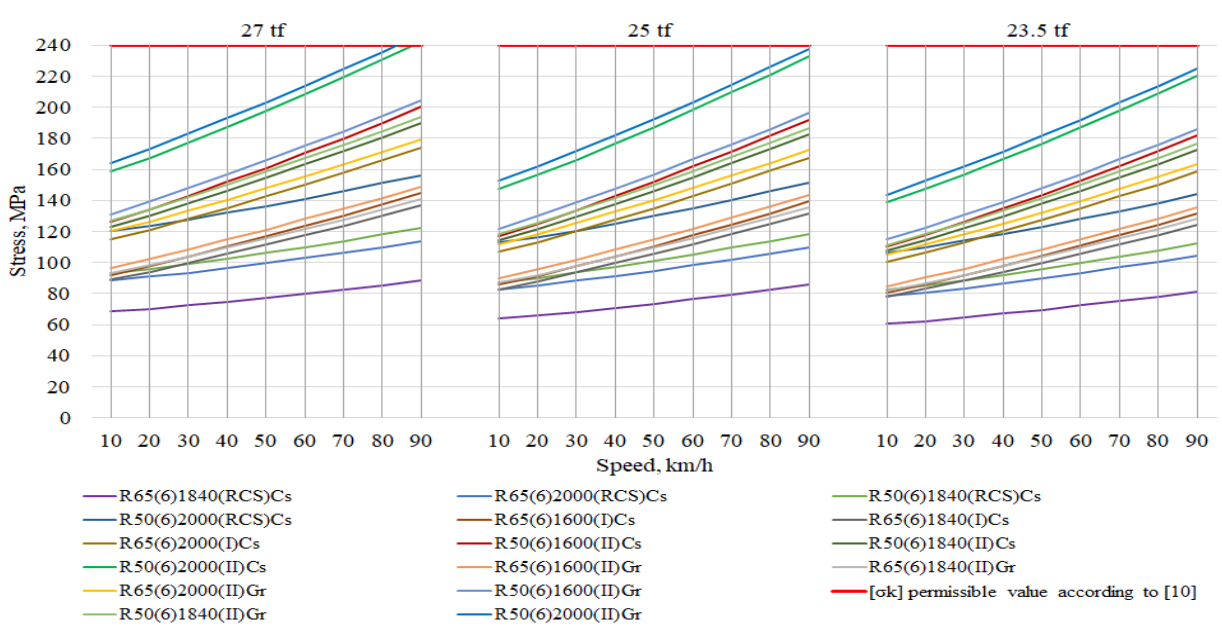

Fig. 3. Dependence of the maximum stresses arising in the edges of the rail foot from the speed of the rolling stock.

The stresses in wooden sleepers (rubber under-rail pads on reinforced concrete) under pads following the Methodology [4] are determined by the formula:

$$
\sigma_{s l}=\frac{k l_{s l}}{2 \omega}\left(P_{d i n}^{\max }+\sum \eta_{i} P_{a v}\right)
$$


where $l_{s l}$ is the distance between the axles of adjacent sleepers; $\omega$ is area of under-rail pad; $\eta_{i}$ is ordinates of the line of influence of rail deflections in track profile.

The dependences of the maximum stresses in wooden sleepers (rubber under-rail pads on reinforced concrete) from the speed of the rolling stock, obtained by formula (3), are shown in figure 4.

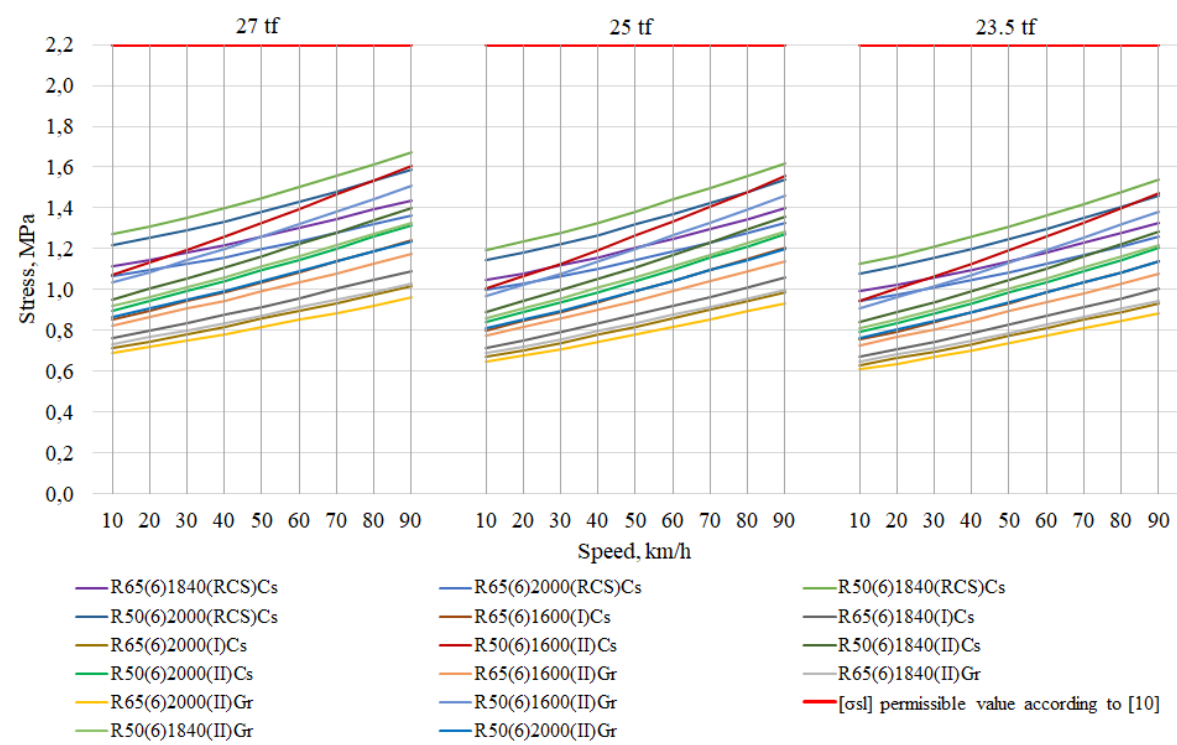

Fig.4. Dependence of the maximum stresses arising in wooden sleepers (rubber under-rail pads on reinforced concrete) from the speed of the rolling stock.

It has been determined that the maximum stresses arising in wooden sleepers (rubber under-rail pads on reinforced concrete) under the lining in all considered rail track structures do not exceed the established allowable values of $2.2 \mathrm{MPa}$ according to GOST R 55050-2012 [5] when operating freight wagons with an axle load of up to 27 tf vehicle with the speed of $90 \mathrm{~km} / \mathrm{h}$, which meets the requirements of the RTO [12].

The maximum stresses in the ballast under the sleeper in accordance with the Methodology [4] is determined by the expression

$$
\sigma_{b}=\frac{Q}{\Omega}=\frac{k l_{s l}}{2 \Omega}\left(P_{d i n}^{\max }+\sum \eta_{i} P_{a v}\right)
$$

where $Q$ is the maximum effort on the sleeper; $\Omega$ is the area of the half-sleeper, taking into account the correction for its bending, $\mathrm{cm}^{2}$.

Figure 5 shows the calculation results obtained by formula (4). It was determined that the maximum stresses arising in the ballast under the sleeper in all the track structures under consideration, except for the R50(6)1600(II)Gr track design, do not exceed the established permissible values of $0.5 \mathrm{MPa}(0.3 \mathrm{MPa}$ for a track with gravel ballast) according to GOST R 55050-2012 [5] when operating freight wagons with an increased axle load of up to $27 \mathrm{tf}$ at a speed of up to $90 \mathrm{~km} / \mathrm{h}$, which meets the requirements of the RTO [12]. On tracks with the R50 (6)1600(II)Gr structure for not exceeding the stresses arising in the gravel ballast under the sleeper, the established permissible values of $0.3 \mathrm{MPa}$ following GOST R 55050-2012 [5] when operating freight wagons with an axle load of up to $27 \mathrm{tf}$ the vehicle must reduce the speed of movement to $80 \mathrm{~km} / \mathrm{h}$ (figure $5, b$ ). 
$a$
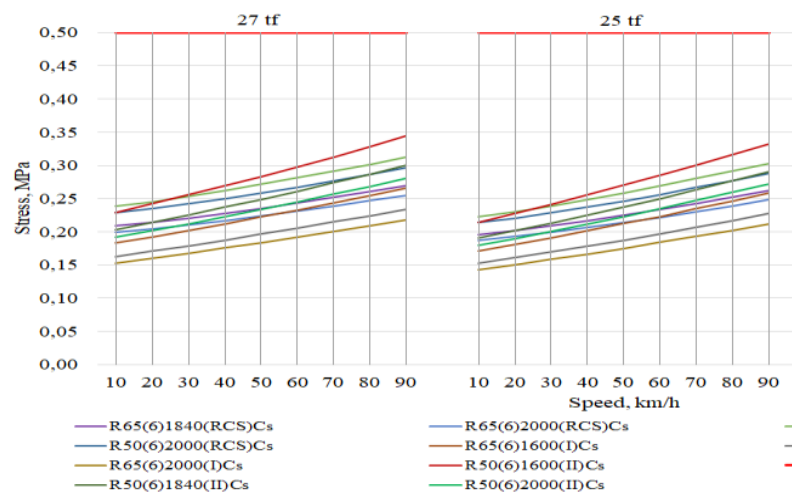

- R65(6)2000(RCS)Cs

R65(6)1600(1)Cs

- R50(6)2000(II)Cs

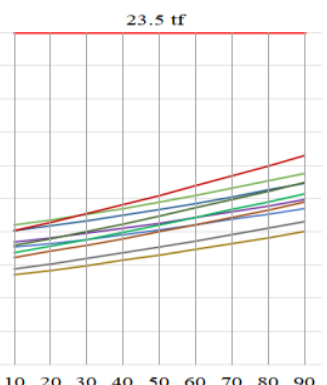

$\begin{array}{llllllllll}10 & 20 & 30 & 40 & 50 & 60 & 70 & 80 & 90\end{array}$

R50(6) 1840 (RCS)C
$-\mathrm{R} 65(6) 1840$ (I)Cs

[ob] permissible value according to [10]

$b$

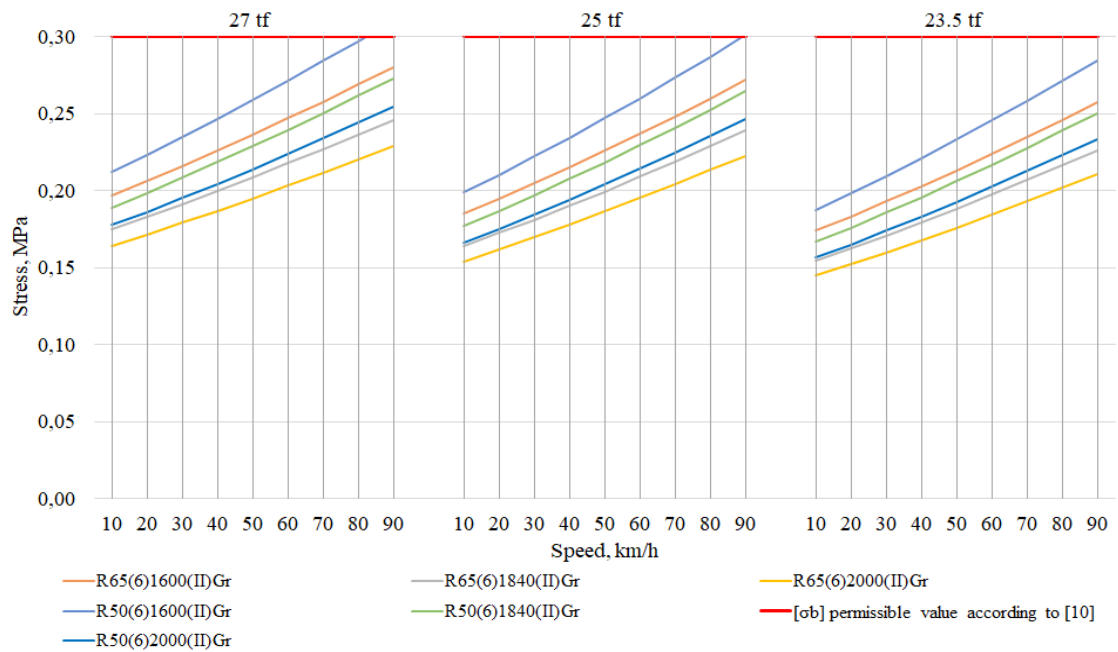

Fig.5. Dependence of the maximum stresses arising in the ballast under the sleeper on the speed of the rolling stock: $a$ is for crushed stone ballast; $b$ is for gravel ballast.

Normal stresses $\sigma_{h}$ in the main area of the subgrade bed at a depth $\mathrm{h}$ from the foot of the sleeper in the rail zone along the calculated vertical in accordance with the Methodology [4] are determined by the expression

$$
\sigma_{h}=\sigma_{h 1}+\sigma_{h 2}+\sigma_{h 3}
$$

Here $\sigma_{h 1}$ and $\sigma_{h 3}$ are stresses from the impact of the $1^{\text {st }}$ and $3^{\text {rd }}$ sleepers, respectively, lying on both sides of the second (calculated) sleeper; $\sigma_{h 2}$ is stresses from the impact of the second sleeper in the profile of the track under the design wheel

$$
\sigma_{h 2}=\sigma_{b} z\left[2.55 C_{2}+\left(0.635 C_{1}-1.275 C_{2}\right) m\right]
$$

where $z$ is a coefficient that takes into account the uneven distribution of pressure along the sleeper and the spatial distribution of the load; $m$ is the transition coefficient from the pressure on the ballast averaged over the width of the sleeper to the pressure under the axis of the sleeper; $\mathrm{C}_{1}, \mathrm{C}_{2}$ are coefficients that take into account the width of the sleepers bed 
and the depth of the ballast layer; $\sigma_{b}$ is the stress in ballast under the calculated (second) sleeper, averaged over the width of the sleeper.

The calculation results obtained by expression (5) are shown in figure 6 .

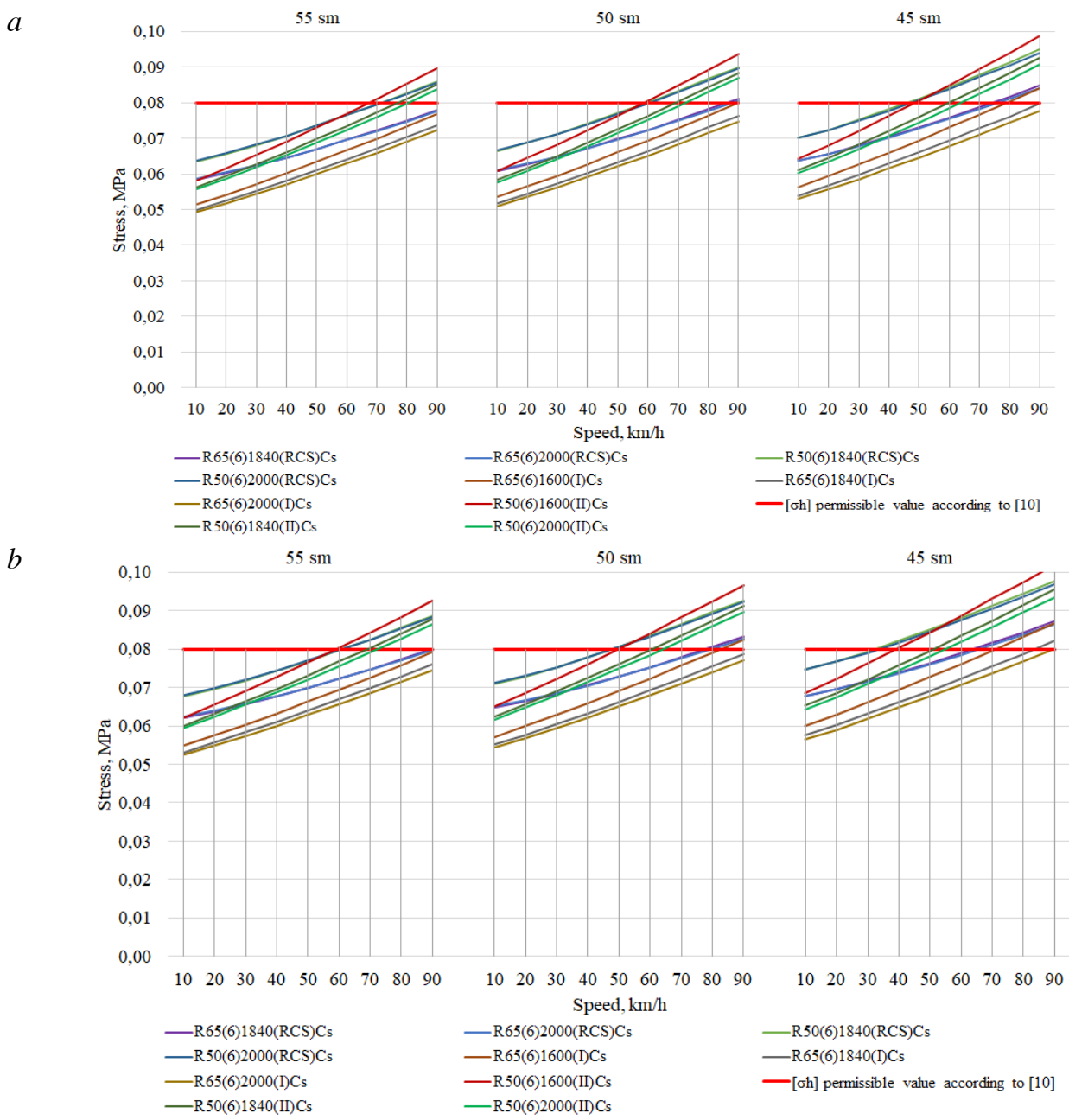

Fig. 6. Dependence of the maximum stresses arising in the main area of the roadbed on the speed of the rolling stock with axial loads of $25 \mathrm{tf}(a)$ and $27 \mathrm{tf}(b)$ on crushed stone ballast.

The results of the research showed that the stresses in the main area of the sub-grade bed on the main tracks of the railways of the Republic of Uzbekistan, where the track mainly has a structure with rails of the R65 type and heavier, laid on reinforced concrete sleepers and type I wooden sleepers with a sleeper pattern of $1840 \mathrm{pcs} / \mathrm{km}$ and more on crushed stone ballast with the thickness of at least $55 \mathrm{~cm}$, taking into account a ballast cushion of sand with the thickness of $20 \mathrm{~cm}$ (R65(6)1840(RCS)Cs, R65(6)2000(RCS)Cs, R65(6)1840(I)Cs and R65(6)2000(I)Cs), do not exceed the established allowed values of $0.08 \mathrm{MPa}$ according to GOST R 55050-2012 [5] when operating freight wagons with an axle load of up to $27 \mathrm{tf}$ at a speed of up to $90 \mathrm{~km} / \mathrm{h}$, which meets the requirements of the RTO [12]. At the same time, on tracks with R50 rails (R50(6)1840(RCS)Cs and R50(6)2000(RCS)Cs) with a ballast layer thickness of at least $55 \mathrm{~cm}$ in order not to exceed the stresses arising in the main area of the sub-grade bed, the permissible values $0.08 \mathrm{MPa}$ 
following GOST R 55050-2012 when operating freight wagons with an axle load of $25 \mathrm{tf}$, it is necessary to limit the speed of movement to $70 \mathrm{~km} / \mathrm{h}$, and when operating wagons with an axle load of $27 \mathrm{tf}-$ to $60 \mathrm{~km} / \mathrm{h}$ (figure 6).

It was found that on the station and access tracks included in the balance of JSC "O'zbekiston temir yo'llari" for the operation of freight wagons with an axle load of $25 \mathrm{tf}$ at a speed of up to $40 \mathrm{~km} / \mathrm{h}$, according to [11, 12], on tracks with R50 rails laid on reinforced concrete sleepers (R50(6)1840(RCS)Cs and R50(6)2000(RCS)Cs), the thickness of crushed stone ballast must be at least $45 \mathrm{~cm}$, and for wagons with an axle load of $27 \mathrm{tf}-$ at least 50 $\mathrm{cm}$.

\section{Conclusions}

Thus, the performed research to determine and assess the loading of the elements of the permanent way and sub-grade bed according to the condition of not exceeding their standard values made it possible to establish the permissible speeds of movement of the freight wagons with increased axial loads of 25 and 27 tf on the country's railways, depending on the track design and the thickness of the ballast layer. At the same time, it was stated that the existing structure of the main tracks of the railways of the Republic of Uzbekistan with rails of the R65 type and heavier, laid on reinforced concrete sleepers with a sleeper pattern of $1840 \mathrm{pcs} / \mathrm{km}$ or more on crushed stone ballast with a thickness of at least $55 \mathrm{~cm}$, taking into account a ballast cushion of sand with a thickness of $20 \mathrm{~cm}$, has sufficient strength and allows, without overstressing the elements of the permanent way and sub-grade bed, to operate freight rolling stock with increased axial loads up to $27 \mathrm{tf}$ at a speed of up to $90 \mathrm{~km} / \mathrm{h}$, which meets the requirements of the RTO [12].

To improve the accuracy of measurements of the rolling stock's force impact on the track, it is proposed to apply the method of piecewise continuous registration of vertical and lateral forces from the interaction of the wheel with the rail by measuring the stresses in two sections of the rail [18-21].

Thus, the introduction of the considered rolling stock on the railways of the Republic of Uzbekistan will increase the carrying and throughput capacity of the most loaded sections of the railway network [22, 23], reduce operating costs, increase the volume of freight traffic by rail, which will create conditions for the further development of national railway transport in the implementation of export and transit potentials of the Republic of Uzbekistan.

\section{References}

1. Verigo M F, Kogan A Ya, Interaction of track and rolling stock (Moscow: Transport) p 559. (1986).

2. Chernyshev M A, Practical methods for calculating the path (Moscow: Transport) $\mathrm{p}$ 236. (1967).

3. Shakhunyants G M 1959 Calculations of the upper structure of the track (Moscow: Transzheldorizdat) p 264

4. Zhelnin G G, Methodology for assessing the impact of rolling stock on the track according to the conditions for ensuring its reliability TsPT-52/14 (Moscow: Russian Ministry of Transport) p 40. (2000).

5. GOST R 55050, Railway rolling stock Permissible exposure norms to the railway track and test methods (Moscow: Standartinform) p 15. (2012)

6. Rahimov R V, Assessment of the stress-strain behavior of structural elements of the railway superstructures in the Republic of Uzbekistan during the operation of rolling 
stock with increased axle loads Bulletin of scientific research results. (3) pp 67-88. (2019).

7. Rahimov R V, Estimated determination of indicators of the impact of rolling stock with increased axial loads on the track in the conditions of the railways of the Republic of Uzbekistan Vestnik transporta Povolzhya, 5 (77) pp 23-33. (2019).

8. Rahimov R V, Assessment of the force impact of rolling stock with increased axial loads on the upper structure of the railway track of the Republic of Uzbekistan Proc. of the XIV Int. Scientific and Technical Conf. "Rolling Stock of the XXI century: ideas, requirements, projects" (Saint Petersburg: Petersburg State Transport University) pp 269-272. (2019)

9. Rahimov R V, Ruzmetov Ya O, Assessment of the impact of the rolling stock with increased axial loads on a way and setting the conditions of their circulation on the railways of the Republic of Uzbekistan Railway transport, topical issues and innovations, (1-2). pp 5-13. (2019).

10. Rahimov R V, Development of heavy traffic and assessment of the impact of the rolling stock with increased axial loads on the upper structure of the railway track of the Republic of Uzbekistan Proc. of the LXXIX All-Russian Scientific and Technical Conf. of students, postgraduates and young scientists "Transport: problems, ideas, prospects" (Saint Petersburg: Petersburg State Transport University) pp 54-56 (2019).

11. Instructions for train movement and shunting work on the railways of the Republic of Uzbekistan (Tashkent: Uzgoszheldornadzor, 2014) p 165 (2014)

12. Rules for the technical operation of railways of the Republic of Uzbekistan (Tashkent: Uzgoszheldornadzor,

13. KMK 2.05.01-96. Railways of $1520 \mathrm{~mm}$ gauge. Design Standards (Tashkent: Goskomarchitectstroy, 1998) p 98. (1998).

14. General technical regulations "On the safety of railway transport during technical operation" approved by the Resolution of the Cabinet of Ministers of the Republic of Uzbekistan dated 04.07.2012 (192) p 120 [Electronic resource] Access mode: http://lex.uz/docs/2026316 (accessed: 27.02.2021). (2021).

15. Orlova A M, Practical evaluation of the life test modes of the 18-9855 bogie side frames on the spatial loading test bench Wagons and Carriage Facilities. 4 (40) pp 3637. (2014).

16. Orlova A M, Rudakova E A, Gusev A V, Improvement of spring suspension of freight cars, taking into account the need to reduce the impact on the track Proceedings of Petersburg Transport University. 15 (1) pp 72-81. (2018).

17. GOST 33211 2014. Freight wagons. Requirements to structural strength and dynamic qualities (Moscow: Standartinform) p 54. (2014).

18. Boronenko Yu P, Povolotskaia G A, Rahimov R V, Zhitkov Yu B, Diagnostics of freight cars using on-track measurements Advances in Dynamics of Vehicles on Roads and Tracks Proc. of the $26^{\text {th }}$ Symp. of the Int. Association of Vehicle System Dynamics Lecture Notes in Mechanical Engineering (Gothenburg, Sweden: Springer, Cham) pp 164-169. (2020)

19. Boronenko Yu P, Rahimov R V, Lafta W M, Dmitriev S V, Belyankin A V, Sergeev $\mathrm{D}$ A, Continuous monitoring of the wheel-rail contact vertical forces by using a variable measurement scale, Proc. of the 2020 Joint Rail Conf. (St. Louis, Missouri, ASME) pp 1-3

20. Boronenko Yu P, Rahimov R V, Petrov A A, Piecewise continuous force measurement between wheel and rail of shear stress in two rail sections, Transport of the Russian Federation. 3 (76) pp 58-64. (2018).

21. Boronenko Yu P, Rahimov R V, Measuring side loading from wheels to rails, Transport of the Russian Federation. 4 (83) pp 45-50. (2019). 
22. Rahimov R V, Wagon fleet of Uzbekistan's railways Transport of the Russian Federation, 1 (74) pp 71-74. (2018).

23. Rahimov R V, Ruzmetov Ya O, Analysis of the state and prospects of the development of the freight wagon fleet of the Republic of Uzbekistan Non-Ferrous Metals, 44 (1) pp 7-11. (2018) 